\title{
Comparison of hemodiafiltration and haemodialysis in patients with uraemic
} pruritus

\section{Mohammed Abdelrazek Elsenbsy ${ }^{\mathrm{a}, \mathrm{c}}$, Abdel Rahman Abdel hamed Elsayed ${ }^{\mathrm{b}}$, Ahmed Mohamed Mohamed Younis ${ }^{\text {a }}$, AbdelKader Ahmed Hashim ${ }^{a}$}

aDepartment of Internal Medicine, Faculty of Medicine, South Valley University, Qena, Egypt.

${ }^{b}$ Department of Clinical Pathology, Faculty of Medicine, South Valley University, Qena, Egypt.

'Internal Medicine Department ,Arabian Gulf University(AGU),Bahrain.

\section{Abstract:}

Background: Chronic kidney disease (CKD)-associated pruritus is a common complicationin patients with end-stage renal disease.

Objectives: To compare the capabilities of hemodialysis (HD) and hemodiafiltration(HDF) in clearing toxins and their effects on pruritus in uremic patients.

Patients and methods: The study included 40 adult subjects (18 years or older) who had maintenance dialysis for at least three months. Patients were divided into two groups: Group I: 20 patients underwent maintenance HDF (Intervention group), Group II: 20 patients underwent maintenance HD (Control group). Serum calcium levels, serum phosphorus levels, serum parathormone levels (PTH) and serum B2 microglobulin were assessed. The severity of pruritus measured by the visual analogue scale (VAS).

Results: The prevalence of Uremic Pruritus in our study was 52.5\% in all studied patients. We found a statistically significant difference $(p$-value $<0.05)$ between studied groups as regard Uremic Pruritis. The prevalence of UP was higher in HD group (70 \%) in compare with HDF group (35\%). We found a Statistically significant difference ( $\mathrm{p}$-value $<0.05$ ) between HDF group \& HD group regard B2 mico-globulin \&PTH. Levels of PTH and B2 microglobulin were significantly higher in HD group $(175.2 \pm 36.1 \mathrm{pg} / \mathrm{ml}$ and $11.3 \pm 2.1 \mu \mathrm{g} / \mathrm{ml}$, respectively) as compared with HDF group (207.9 $\pm 36.4 \mathrm{pg} / \mathrm{ml}$ and $14.1 \pm 4.04 \mu \mathrm{g} / \mathrm{ml}$, respectively).

Conclusion: The prevalence and severity of Uremic Pruritus were significantly lower among HDF patients than HD patients. HDF can clear b2-MG and PTH and provide relief from pruritus efficiently more than HD.

Key Words: Hemodialysis, Hemodiafiltration, Uremic pruritus.

\section{Introduction}

In chronic hemodialysis patients, uremic pruritus is a well-known symptom that has a detrimental effect on quality of life and longevity. Despite advances in dialysis technologies, the prevalence of uremic pruritus remains extremely high (Mettang and Kremer, 2015).

Xerosis, divalent ions, calcium-phosphate compound. high C-reactive protein. hepatitis, hyperparathyroidism, immune derangement, and opioid system alteration have all been linked to uremic pruritus in previous trials (Ko et al., 2013). The cause of uremic pruritus, on the other hand, is also unknown. Antihistamines, steroids, emollients, charcoal, erythropoietin, and ultraviolet phototherapy are also common therapies for uremic pruritus (Attia and Hassan. 2014). 
Unlikely, existing treatment choices for uremic pruritus are minimal and unsatisfactory due to a lack of understanding. Pruritus is more prevalent in under-dialyzed patients, and can be helped by increasing dialysis effectiveness (Zhang et al., 2016).

Online hemodiafiltration is an increasingly applied dialysis modality, especially in Europe1. This is most likely caused by the fact that sterile dialysis fluids can now be produced on-line (Vanholder et al., 2008). HDF has the advantage of combining clearance of small molecular weight substances by diffusion, with clearance of middle- and large molecular weight substances by convection (Vilar et al., 2009). HDF requires the use of synthetic high-flux membranes and ultrapure dialysate and sterile substitution fluids. Several studies suggest a potential benefit for patients treated with HDF (Penne et al., 2009). It is hypothesized that increased clearance of a broader range of uremic substances leads to less inflammation, oxidative stress and endothelial dysfunction, which will result in less morbidity and mortality (Blankestijn et al., 2010). The aim of our study was to compare the capabilities of HD and HDF in clearing toxins and their effects on pruritus in uremic patients.

\section{Patients and methods}

This study was a prospective observational study conducted in Department of Internal Medicine, Qena University Hospital between December 2019 and July 2020.

The study included 40 adult subjects (18 years or older) who were undergoing maintenance dialysis for at least three months. Patients were divided according to dialysis modality into two groups: Group I: 20 patients were receiving maintenance HDF (Intervention group), Group II: 20 patients were receiving maintenance HD (Control group).All patients signed a written informed consent prior to inclusion into this study and institutional ethical committee in Qena Faculty of Medicine approved the study.

\section{Exclusion criteria}

- Patients with chronic skin diseases.

- Patients with chronic liver disease.

- Patients with metabolic disorders or other diseases related to systemic pruritus.

- Patients with systemic malignancies

- Those receiving chronic opiate therapy or corticosteroids.

Patients were subjected to the following:

1. History taking.

2. Clinical examination.

3. Laboratory Investigations:-Venous blood samples $(5-10 \mathrm{~mL})$ were taken in a pyrogen free vacutainer tubes under sterile conditions from patients before dialysis session. Serum was obtained from freshly drawn, rapidly centrifuged sample and quickly frozen at $-20^{\circ} \mathrm{C}$ until processed. Estimation of serum creatinine was done using COBAS 501 chemistry autoanalyzer (Roche Diagnostics, USA). Calcium and Phosphorus measured by photometric test. Parathyroid hormone (PTH) measured by Quantitative, electrochemiluminescence (ECLIA) assay. Beta 2 microglobulin level was measured in all patients before dialysis session by enzyme-linked immunesorbent assay (ELISA) commercial kit 
( $\beta 2 \mathrm{M}$ Enzyme Immunoassay kit, DRG International, Inc., USA).

4. Pruritus assessment: The patients were considered to have uremic pruritus if they had the following: at least 3 episodes of pruritus during a period of $>2$ weeks, with the symptoms occurring a few times a day, lasting at least a few minutes, and troubling the patient; or the regular occurrence of pruritus during a period of 6 months, but less frequently than listed above. The severity of pruritus measured by the visual analogue scale (VAS) from 0 to $10(0=$ no pruritus, $10=$ worst pruritus imaginable) was evaluated from each participant at baseline and follow-up according to a previous report. We used the categorization by Reich et al. as a reference when classifying the VAS score. We classified the severity of pruritus as follows: $<4$ points was considered mild; $\geq 4$ points but $<7$ points was moderate; $\geq 7$ points but $<9$ points severe; and $\geq 9$ points very severe pruritus (Reich et al., 2012).

\section{Statistical analysis}

Data were studied utilizing a Statistical Program for Social Science (SPSS) version 18.0. Quantitative data were evinced as mean \pm standard deviation $(\mathrm{M} \pm \mathrm{SD})$ while qualitative data were evinced as frequency and percentage No(\%) and were be compared by student $\mathrm{t}$ - test. Chi-square test: was utilized in comparison of non-parametric data. P- values were established statistically significant at $\mathrm{P}<0.05$.

\section{Results}

\section{Baseline characteristics:}

Among HD group, Mean patient age was $50.6 \pm 10.1$ years, $55 \%$ were male, mean BMI was 29.2. The mean dialysis vintage was $32.3 \pm 16.4$ months. Among HDF group, mean patient age was $49.4 \pm$ 9.8years, $60 \%$ were male, mean BMI was 29.4. The mean dialysis vintage was $33.5 \pm$ 16.4 months.

There was no significant difference found regarding age, gender, duration of dialysis, and BMI.

The prevalence of Uremic Pruritus in our study was $52.5 \%(21 / 40)$ in all studied patients (table 2).

The results of current study showed statistically significant difference ( $p$-value < 0.05 ) between studied groups as regard Uremic Pruritis. The prevalence of UP was higher in HD group in comparison with HDF group (table 3).

The results of current study observed that statistically significant difference ( $p$ value $<0.05$ ) between HDF group \& HD group regard B2 mico-globulin \&PTH. Levels of PTH and B2 microglobulin were significantly higher in HD group (175.2 \pm $36.1 \mathrm{pg} / \mathrm{ml}$ and $11.3 \pm 2.1 \mu \mathrm{g} / \mathrm{ml}$, respectively) as compared with HDF group $(207.9 \pm 36.4 \mathrm{pg} / \mathrm{ml}$ and $14.1 \pm 4.04 \mu \mathrm{g} / \mathrm{ml}$, respectively) (table 4$)$. 
Table. 1. Description of demographic data in studied groups

\begin{tabular}{|c|c|c|c|c|c|c|}
\hline \multicolumn{2}{|c|}{ Variables } & \multirow{2}{*}{\multicolumn{2}{|c|}{$\begin{array}{c}\text { HDF group } \\
(\mathbf{N}=\mathbf{2 0})\end{array}$}} & \multirow{2}{*}{\multicolumn{2}{|c|}{$\begin{array}{c}\begin{array}{c}\text { HD group } \\
(\mathbf{N}=\mathbf{2 0})\end{array} \\
49.8 \\
\end{array}$}} & P-value \\
\hline \multirow[b]{2}{*}{ Age (years) } & Mean & & & & & \multirow[b]{2}{*}{$0.801 \mathrm{NS}$} \\
\hline & $\pm \mathrm{SD}$ & \multicolumn{2}{|c|}{10.1} & \multicolumn{2}{|c|}{9.8} & \\
\hline \multirow[b]{2}{*}{ Sex } & Male & 11 & $55 \%$ & 21 & $60 \%$ & \multirow[b]{2}{*}{$0.749 \mathrm{NS}$} \\
\hline & Female & 9 & $45 \%$ & 8 & $40 \%$ & \\
\hline \multirow[b]{2}{*}{ BMI $\left(\mathrm{kg} / \mathrm{m}^{2}\right)$} & Mean & \multicolumn{2}{|c|}{29.2} & \multicolumn{2}{|c|}{29.4} & \multirow[b]{2}{*}{$0.748 \mathrm{NS}$} \\
\hline & $\pm \mathrm{SD}$ & \multicolumn{2}{|c|}{3.01} & \multicolumn{2}{|c|}{2.7} & \\
\hline \multirow{2}{*}{$\begin{array}{c}\text { Dialysis } \\
\text { vintage (months) }\end{array}$} & Mean & \multicolumn{2}{|c|}{32.3} & \multicolumn{2}{|c|}{33.5} & \\
\hline & \pm SD & \multicolumn{2}{|c|}{16.4} & \multicolumn{2}{|c|}{16.4} & $0.818 \mathrm{NS}$ \\
\hline
\end{tabular}

This table shows No statistical significant difference ( $p$-value $>0.05)$ between studied groups as regard age, sex, BMI and Dialysis vintage.

Table 2. Prevalence of uremic pruritis in all studied patients

\begin{tabular}{|l|c|c|c|}
\hline \multicolumn{2}{|c|}{ Variables } & \multicolumn{2}{c|}{ Patients (N=40) } \\
\hline \multirow{3}{*}{ Uremic Pruritis } & No & 19 & $47.5 \%$ \\
\cline { 2 - 4 } & Yes & 21 & $52.5 \%$ \\
\hline
\end{tabular}

This table shows prevalence of Uremic Pruritis in all studied patients $(52.5 \%)$.

Table 3. Comparison between studied groups as regard prevalence of Uremic Pruritis and VAS

\begin{tabular}{|c|c|c|c|c|c|c|}
\hline \multicolumn{2}{|c|}{ Variables } & \multicolumn{2}{|c|}{$\begin{array}{c}\text { HDF group } \\
(\mathbf{N}=\mathbf{2 0})\end{array}$} & \multicolumn{2}{|c|}{$\begin{array}{c}\text { HD group } \\
(\mathbf{N}=\mathbf{2 0})\end{array}$} & P-value \\
\hline \multirow{2}{*}{$\begin{array}{l}\text { Uremic } \\
\text { Pruritis }\end{array}$} & $\mathrm{No}$ & 13 & $65 \%$ & 6 & $30 \%$ & \multirow[t]{2}{*}{$0.026 \mathrm{~S}$} \\
\hline & Yes & 7 & $35 \%$ & 14 & $70 \%$ & \\
\hline VAS score* & Mean \pm SD & \multicolumn{2}{|c|}{$1.95 \pm 1.8$} & \multicolumn{2}{|c|}{$3.8 \pm 1.5$} & $0.002 \mathrm{~S}$ \\
\hline
\end{tabular}

*VAS = visual analog scale

This table shows statistically significant difference $(\mathbf{p}$-value $<\mathbf{0 . 0 5})$ between studied groups as regard prevalence of Uremic Pruritis and VAS.

Table 4. Comparison between studied groups as regard laboratory data

\begin{tabular}{|c|c|c|c|c|}
\hline \multicolumn{2}{|l|}{ Variables } & $\begin{array}{l}\text { Group I } \\
(\mathbf{N}=\mathbf{2 0})\end{array}$ & $\begin{array}{l}\text { Group II } \\
(\mathbf{N}=\mathbf{2 0})\end{array}$ & P-value \\
\hline \multirow[t]{2}{*}{ Calcium (mg/dl) } & Mean & 8.5 & 8.3 & \multirow[b]{2}{*}{$0.351 \mathrm{NS}$} \\
\hline & $\pm \mathrm{SD}$ & 0.7 & 0.6 & \\
\hline \multirow[t]{2}{*}{ Phosphorus (mmol/L) } & Mean & 4.9 & 5.1 & \multirow[b]{2}{*}{$0.344 \mathrm{NS}$} \\
\hline & $\pm \mathrm{SD}$ & 1.0 & 0.7 & \\
\hline \multirow{2}{*}{$\begin{array}{l}\text { B2 micriglobulin } \\
(\mu \mathrm{g} / \mathrm{ml})\end{array}$} & Mean & 11.3 & 14.1 & \multirow[b]{2}{*}{$0.008 \mathrm{~S}$} \\
\hline & $\pm \mathrm{SD}$ & 2.1 & 4.04 & \\
\hline \multirow[t]{2}{*}{ PTH (pg/ml) } & Mean & 175.2 & 207.9 & \multirow[b]{2}{*}{$0.007 \mathrm{~S}$} \\
\hline & $\pm \mathrm{SD}$ & 36.1 & 36.4 & \\
\hline
\end{tabular}

This table shows that levels of PTH and B2 microglobulin were significantly higher in HD group as compared with HDF group (p-value $<0.05$ ). 


\section{Discussion:}

Chronic kidney disease (CKD)associated pruritus is one of the common symptoms observed in CKD patients undergoing dialysis. Chronic pruritus significantly impairs the quality of life of CKD patients by exerting deteriorating effects on the physical, psychological, social, and functional wellbeing of these individuals (Rehman et al., 2019).

Uremic Pruritus was found to be prevalent in $52.5 \%(21 / 40)$ of the patients in our sample.

In a case-series analysis, Sanad et al. tested 100 patients with CRF on normal HD to determine the prevalence and pattern of cutaneous manifestations. The patients consisted of 66 men and 34 women. Their ages ranged from 15 to 65 years old. Pruritus was present in $52 \%$ of the patients' surveyed (Sanad et al. 2014).

Mourad et al. conducted a study on 93 patients with End Stage Renal Disease on HD in Our area; 56 males (60.2\%) and 37 females $(39.8 \%)$, with a ratio of $1.5: 1$. Their ages ranged from 18 to 80 years, with a mean of $50.23 \pm 14.10$ years, and their HD lasted between 0.5 and 180 months, with a mean of $38.77 \pm 10.6$ months (Mourad et al., 2014). Sultan et al. reported that pruritus was found in $55 \%$ of their HD patients (Sultan et al., 2010).

Ozen et al. conducted a study on 249 dialysis patients from four different clinics. The average patient age was $62.54 \pm 12.7$ years old, with 54.1 percent of patients being male and a mean dialysis period of 61.3543 .3 months. Pruritus was found in 53.4 percent of patients on hemodialysis (Ozen et al., 2018).
The results of current study showed statistically significant difference (p-value $<\mathbf{0 . 0 5}$ ) between studied groups as regard Uremic Pruritis. The prevalence of UP was higher in HD group (70 \%) in compare with HDF group (35\%).

Zhang et al. included 40 pruritic maintenance HD patients (30 males and 10 females). The patients were randomly assigned to one of two groups: hemodialysis with hemoperfusion $(\mathrm{HP}+\mathrm{HD})$ or hemodiafiltration with hemoperfusion (HP+HDF). There were no statistical differences between the two groups in terms of age, ethnicity, dialysis length, ESRD etiology, hemoglobin, albumin, and C-reactive protein. HP+HD lowered itch from a mean VAS score of 8.06 (range, 6.8-9.32) to 5.03 (range, 3.736.33), while HP+HDF inhibited itch from a mean VAS score of 8.08 (range, 6.73-9.43) to 3.21 (range, 2.11-4.31) after 12 weeks of therapy $(\mathrm{P}<0.05)$. Furthermore, the $\mathrm{HP}+\mathrm{HD}$ and HP+HDF classes had 75 percent and 100 percent pruritus remission frequencies, respectively $(\mathrm{P}<0.05)$ (Zhang et al. 2016).

The present analysis found a statistically significant difference ( $p$-value 0.05 ) between the HDF and HD groups in terms of b2-MG and PTH. PTH and b2MG levels were higher in HD than in HDF.

Kora et al., who recently published data from an Egyptian population on maintenance dialysis, backed up the findings of the current research. They had 100 patients who were split into two categories. HD was used on 60 patients in Group I. A total of 40 patients in Group II were on HDF. They revealed a highly statistically significant difference $(\mathrm{P}$ value 0.001) in the mean of PTH and b2-MG 
between two groups, with a high level of PTH and b2-MG in the HD group versus the HDF group(Kora et al., 2020).

Jin et al. found that after 12 weeks of dialysis, the HDF and PD groups had slightly lower b2-MG and PTH levels than the HD group (both $\mathrm{p}$ 0.05). In comparison to the HP+HD group, serum creatinine, BUN, phosphates, PTH, and 2microglobulin were found to be slightly lower in the HP+HDF group. They showed that post-dialysis 2-microglobulin levels fell by $64 \%$ in the HP+HD group and $37 \%$ in the HP+HDF group, respectively. After combining HP and HDF treatment, 2microglobulin clearance was extremely successful.

\section{Conclusion}

The prevalence and severity of uremic pruritus were lower among HDF patients than HD patients. Increased PTH and B2MGamong patients underwent were HD and they were risk factors for UP development in CKD patients.HDF can clear b2-MG and PTH and provide relief from pruritus efficiently more than HD.

\section{Conflict of Interest:}

The authors of the study have no conflict of interest related to this publication.

\section{References:}

1. Attia EA, Hassan AA (2014): Uremic pruritus pathogenesis, revisited. Arab J Nephrol Transplant, 7: 91-99.

2. Blankestijn PJ, Ledebo I, Canaud B (2010):Hemodiafiltration: clinical evidence and remaining questions. Kidney Int, 77: 581-587

3. Jin DH, Shen HY, Feng S, Zhan ZB, Jiang LS, Qiu BF, et al. (2014): Treatment effects of different incident dialysis modalities on pruritus in elderly uremic patients. International Journal of Gerontology, 8(4), 223-227.

4. Ko MJ, Wu HY, Chen HY, Chiu YL, Hsu SP, Pai MF, et al. (2013): Uremic pruritus, dialysis adequacy, and metabolic profiles in hemodialysis patients: a prospective 5-year cohort study. PLoS One, 8: e71404.

5. Kora MA, Tawfeek AR, Kasem HE, El Gendy MSK (2020): Study of the Effect of Haemodiafiltration on the CKD-MBD in Regular Haemodialysis Patients. J Am Sci, 16(7):20-25

6. Mettang T, Kremer AE (2015): Uremic pruritus. Kidney international, 87(4), 685-691.

7. Mourad B, Hegab D, Okasha K, Rizk S (2014): Prospective study on prevalence of dermatological changes in patients under hemodialysis in hemodialysis units in Tanta University hospitals, Egypt. Clinical, cosmetic and investigational dermatology, 7, 313319.

8. Ozen N, Cinar FI, Askin D, Mut D (2018): Uremic pruritus and associated factors in hemodialysis patients: A multi-center study. Kidney research and clinical practice, 37(2), 138-147.

9. Penne EL, van BT, van der Weerd NC, Grooteman MP, Blankestijn PJ (2009): Optimizing haemodiafiltration: tools, strategy and remaining questions. Nephrol Dial Transplant, 24: 3579-3581

10. Rehman IU, Chan KG, Munib S, Lee LH, Khan TM (2019): The association between CKD-associated pruritus and quality of life in patients undergoing hemodialysis in Pakistan. Medicine, 98:36(e16812).

\section{Sultan MM, Mansour HH,} Wahby IM, Houdery AS (2010): Cutaneous manifestations in Egyptian patients with chronic renal failure on 
regular haemodialysis. J Egypt Women Dermatol Soc, 7(1):49-55.

12. Vanholder R, Van LS, Glorieux G (2008): The middle-molecule hypothesis 30 years after: lost and rediscovered in the universe of uremic toxicity? J Nephrol , 21: 146160

13. Vilar E, Fry AC, Wellsted D, Tattersall JE, Greenwood RN, Farrington K (2009): Long- Term Outcomes in Online Hemodiafiltration and High-Flux Hemodialysis: A Comparative Analysis. Clin J Am SocNephrol, 4: 1944-1953

14. Zhang J, Yuan Y, An X, Ouyang C, Ren H, Yang G. et al. (2016): Comparison of combined blood purification techniques in treatment of dialysis patients with uraemic pruritus. Int J ClinExp Med, 9(5): 8563-8568. 